\title{
Local control without resection
}

\author{
Thomas A. D'Amico, MD
}

See related article on page 929 .
From the Department of Surgery, Duke University Medical Center, Durham, NC.

Received for publication Sept 9, 2002; accepted for publication Sept 19, 2002.

Address for reprints: Thomas A. D'Amico, MD, Duke University Medical Center, Department of Surgery, Box 3496, Durham, NC 27710 (E-mail: damic001@ mc.duke.edu).

J Thorac Cardiovasc Surg 2003;125:787-8

Copyright (C) 2003 by The American Association for Thoracic Surgery

0022-5223/2003\$30.00+0

doi: $10.1067 / \mathrm{mtc} .2003 .258$

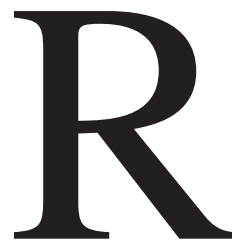

esection of early-stage non-small cell lung cancer (NSCLC) remains the standard of care for patients whose condition is considered operable on the basis of the following criteria: Complete (R0) resection is technically achievable; postresection pulmonary function is adequate; and coexisting medical conditions do not contraindicate general anesthesia and surgery. Although anatomic resection is considered the optimal procedure for NSCLC, some patients, who could not tolerate lobectomy, may nevertheless benefit from more limited (wedge) resection. In addition, selected patients with isolated pulmonary metastases may benefit from limited pulmonary resection, based on the following criteria: The primary malignant tumor is controlled; there is no evidence of extrathoracic disease; the pulmonary involvement is considered completely resectable with adequate postresection pulmonary reserve; and no other therapy (medical) is considered effective.

Despite advances in perioperative care and understanding regarding operability for patients with advanced pulmonary dysfunction, ${ }^{1}$ some patients with potentially curable disease are not candidates for surgical resection because of coexisting medical conditions. External beam radiation is considered the most reasonable alternative for patients with early-stage lung cancer who are not operative candidates; however, regional complications such as radiation pneumonitis, fibrosis, and esophagitis may limit efficacy. Furthermore, conventional radiation therapy is not indicated for pulmonary metastases.

Noninvasive strategies, applicable to patients considered "medically inoperable," that are being developed to manage malignant pulmonary disease include stereotactic radiotherapy, brachytherapy, photodynamic therapy, bronchial artery infusion of chemotherapy, cryotherapy, and radiofrequency ablation (RFA). As these techniques evolve, one would expect application to patients whose malignant tumors should be considered operable and completely resectable. Thus, the development of these techniques must be scrutinized to ascertain safety, efficacy, and applicability.

In this issue of the Journal, the efficacy of RFA for malignant pulmonary disease, including early-stage lung cancer and isolated pulmonary metastases, is examined in patients who could not tolerate pulmonary resection. ${ }^{2}$ This study is important because it emphasizes the role of thoracic surgeons in evaluating nonoperative strategies in this population; emerging technologies are already being investigated and applied by others. RFA, which already has been accepted for the treatment of hepatic malignant disease, is being advanced for treatment of pulmonary malignancy by interventional radiologists. As well, other nonsurgical therapies are being developed for patients with early-stage lung cancer, such as stereotactic radiosurgery by radiation oncologists ${ }^{3}$ and photodynamic therapy by pulmonologists. ${ }^{4}$ Thoracic surgeons should be involved with the evaluation of these new technologic advances, and the authors should be commended for their effort.

RFA does appear to be safe, at least under the conditions of this study, in which an operating room equipped with a computed tomographic scanner was used. It is difficult to ascertain the efficacy of RFA in the current study, as there are no defined exclusion criteria. It appears that patients were included in this study who would not have been offered any type of therapy, even if medically operable, under the premise that RFA carries such a minimal risk. As well, it is not clear that patients who recently received other therapy were uniformly excluded. Clearly, at least one patient received recent brachytherapy. Treatment response cannot be attributed to RFA if this is the case. Nevertheless, this technology does appear to be effective in selected patients, 
and a formal phase 2 clinical trial, evaluating patients with primary NSCLC less that $5 \mathrm{~cm}$ in diameter or with isolated $(\leq 3)$ pulmonary metastases should be designed.

Most important, the evaluation of technologies to achieve nonsurgical local control of malignant pulmonary disease must be designed and conducted by thoracic surgeons, in conjunction with medical oncologists, radiation oncologists, interventional radiologists, and pulmonologists. The investigations must analyze outcome, risk/benefit ratio, and cost and should be designed to answer a scientific question rather than demonstrate a proprietary strategy. The study by Herrera and colleagues ${ }^{2}$ is an important primary step in the evaluation of RFA for the treatment of patients with malignant pulmonary disease who are not considered surgical candidates.

\section{References}

1. Korst RJ, Ginsberg RJ, Ailawadi M, Bains MS, Downey RJ, Jr, Rusch VW, et al. Lobectomy improves ventilatory function in selected patients with severe COPD. Ann Thorac Surg. 1998;66: 898-902.

2. Herrera LJ, Fernando HC, Perry Y, Gooding WE, Buenaventura PO, Christie NA, et al. Radiofrequency ablation of pulmonary malignant tumors in nonsurgical candidates. J Thorac Cardiovasc Surg. 2003; 125:929-37.

3. Uematsu M, Shioda A, Suda A, Fukui T, Ozeki Y, Hama Y, et al. Computed tomography-guided frameless stereotactic radiotherapy for stage I non-small cell lung cancer: a 5-year experience. Int J Radiat Oncol Biol Phys. 2001;51:666-70.

4. Fielding DI, Buonaccorsi GA, MacRobert AJ, Hanby AM, Hetzel MR, Bown SG. Fine-needle interstitial photodynamic therapy of the lung parenchyma: photosensitizer distribution and morphologic effects of treatment. Chest. 1999;115:502-10.

\section{UN THE MOVE?}

Don't miss a single issue of the journal! To ensure prompt service when you change your address, please photocopy and complete the form below.

Please send your change of address notification at least six weeks before your move to ensure continued service. We regret we cannot guarantee replacement of issues missed due to late notification.

\section{JOURNAL TITLE:}

Fill in the title of the journal here.

\section{OLD ADDRESS:}

Affix the address label from a recent issue of the journal here.

\section{NEW ADDRESS:}

Clearly print your new address here.

Name

Address

City/State/ZIP
COPY AND MAIL THIS FORM TO:

Mosby

Subscription Customer Service

6277 Sea Harbor Dr

Orlando, FL 32887
OR FAX TO:

407-363-9661

N/ Mosby
OR PHONE:

800-654-2452

Outside the U.S., call

407-345-4000 